\title{
Acquired hypofibrinogenemia: current perspectives
}

This article was published in the following Dove Press journal:

Journal of Blood Medicine

26 September 2016

Number of times this article has been viewed

\author{
Martin W Besser' \\ Stephen G MacDonald ${ }^{2}$ \\ 'Department of Haematology, \\ ${ }^{2}$ Department of Specialist \\ Haemostasis, The Pathology \\ Partnership, Addenbrooke's Hospital, \\ Cambridge, UK
}

\begin{abstract}
Acquired hypofibrinogenemia is most frequently caused by hemodilution and consumption of clotting factors. The aggressive replacement of fibrinogen has become one of the core principles of modern management of massive hemorrhage. The best method for determining the patient's fibrinogen level remains controversial, and particularly in acquired dysfibrinogenemia, could have major therapeutic implications depending on which quantification method is chosen. This review introduces the available laboratory and point-of-care methods and discusses the relative advantages and limitations. It also discusses current strategies for the correction of hypofibrinogenemia.

Keywords: Clauss fibrinogen assay, fibrinogen antigen, viscoelastic testing, gravimetric fibrinogen assay, PT-derived fibrinogen, functional fibrinogen, direct oral anticoagulant, dysfibrinogenemia, afibrinogenemia
\end{abstract}

\section{Introduction}

The fibrinogen protein is a $45 \mathrm{~nm}$ hexameric arrangement of peptide chains (alpha, beta, and gamma) connected by disulfide bonds, with a molecular weight of approximately $340 \mathrm{kDa}$. The fibrinogen protein consists of two outer $\mathrm{D}$ domains and a central E domain and is encoded by chromosome 4 (Figure 1). ${ }^{1}$

It is one of the most abundant plasma proteins after albumin and immunoglobulins. Normal ranges vary and are typically given as $2-4.5 \mathrm{~g} / \mathrm{dL}$, giving a total body blood fibrinogen in excess of $200 \mathrm{~g}$ in a normal sized adult. ${ }^{2}$ It is produced in the liver and is the main substrate for thrombin. It is formed by the action of thrombin on an area termed "exosite I", in which fibrinopeptides A and B are removed from the N-terminal end of the alpha and beta chains and polymerization ensues. There are three additional low-affinity nonsubstrate-binding sites, two in the E-domain and one in the D-domain of fibrinogen. ${ }^{1}$ The resultant fibrin polymerizes to protofibrils and are cross-linked by the coagulation factor XIIIa. As a result, the protofibrils associate to fibrils.

In its unconverted form, fibrinogen contributes to platelet aggregation by interlinking glycoprotein (Gp) IIb/IIIa receptors of different platelets, and it is an acute phase protein. Moreover, it participates in nonsubstrate thrombin binding and fibrinolysis., ${ }^{2,3}$

Breakdown of cross-linked fibrin molecules results in detectable dimers of D-domains (D-Dimers) and X-linked degradation products, providing objective evidence of significant clot formation in the patient.
Department of Specialist Haemostasis,

The Pathology Partnership,

Addenbrooke's Hospital, Box 234, Hills

Road, Cambridge CB2 0QQ, UK

Tel +44 I223 245 I5 I

Fax +44 I223 217017

Email Stephen.Macdonald@

addenbrookes.nhs.uk 
Low fibrinogen is observed in patients with reduced synthesis due to hepatic impairment or patients with consumption or hemodilution.

Fibrinogen concentrate has an elimination half-life of approximately 80 hours in patients with congenital fibrinogen deficiency. ${ }^{4,5}$ Simple replacement of fibrinogen in the steady state should therefore reliably correct hypofibrinogenemia for a clinically useful time period. If repeated doses are required, this therefore indicates an ongoing state of consumption, absent production, or interference with the assay employed. In case of a massive hemorrhage or hemodilution, the patient is expected to "catch-up" with the acute deficit over time unless the hemorrhage or hemodilution is ongoing or the patient has entered a state of hyperfibrinolysis. This was confirmed in a study using blunt liver injury in pigs where the animals were randomized between fibrinogen concentrate infusion and saline, with early benefits in the treated group no longer evident compared to the untreated group. ${ }^{6}$

Fibrinogen consumption is encountered following snake bites, but as a clinical problem is overall exceedingly rare compared to other causes of hypofibrinogenemia. However, this mechanism of action is exploited in the laboratory in assays such as the atroxin or reptilase time where heparin contamination has to be ruled out to confirm a hypo- or dysfibrinogenemia. Ancrod was also used historically to defibrinate the plasma used in early thrombin generation techniques. ${ }^{7,8}$

Blood loss reduces the fibrinogen level once 1.0-1.5 blood volumes have been lost and replaced. Historically, a fibrinogen level of $1.0 \mathrm{~g} / \mathrm{dL}$ was considered adequate to keep microvascular bleeding at bay. ${ }^{9}$

Acquired hypofibrinogenemia is also observed in acute leukemia. In patients with lymphoblastic leukemia, levels $<1$ $\mathrm{g} / \mathrm{dL}$ were reported in $73 \%$ of patients. ${ }^{10}$ Concurrent reduction in antithrombin levels are also observed, and it is antithrombin that is routinely monitored in patients due to increased thrombotic risk, although acquired hypofibrinogenemia can be used as a marker of decreased synthesis and thrombotic risk. ${ }^{11}$ Increased fibrinopeptide A generation is also seen in the induction phase of asparaginase therapy and indicates activation of coagulation as another reason for the acquired hypofibrinogenemia. ${ }^{12}$

Systemic thrombolytic therapy reduces the fibrinogen level and can be used as an indicator of whether the thrombolytic therapy is effective. ${ }^{13}$

\section{Congenital fibrinogen deficiencies}

There are more than 245 known variants of congenital afibrinogenemia that can be associated with thrombosis or a bleeding tendency. In some cases, afibrinogenemia or dysfibrinogenemia may be entirely asymptomatic.

Dysfibrinogenemia is a complex mixture of hemorrhagic and prothrombotic disorders characterized by an abnormal ratio of fibrinogen concentration measured by clotting based (functional) assays versus assays that measure fibrinogen based on antigen (fibrinogen clotting activity-antigen ratio). Up to $1 \%$ of patients with venous thromboembolic disease suffer with this condition in the background. Interestingly, in the congenital form, the prevalence of thrombosis equals that of bleeding overall, and approximately $30 \%$ of venous thromboembolic disease patients also suffer from bleeding.

Both bleeding and thrombotic disorders are directly linked to the abnormal structure of the molecule and depending on whether the mutation decreases the affinity to thrombin, other fibrinogen molecules or inhibitors of coagulation.

Acquired dysfibrinogenemia is caused by acquired states resulting in an imbalance of fibrinogen mass to fibrinogen function. This can be through posttranslational sialylation as in liver disease or autoantibodies interfering with the polymerization of the fibrinogen molecules such as in systemic lupus erythematosus, myeloma, monoclonal gammopathy of uncertain significance, drug therapy, or may be idiopathic (Table 1). ${ }^{14}$ Bleeding appears to be more prominent in these patients compared to the congenital forms.

\section{Laboratory assays}

Fibrinogen assays have evolved as laboratory technology has advanced. Early methods relied on visual detection of clot

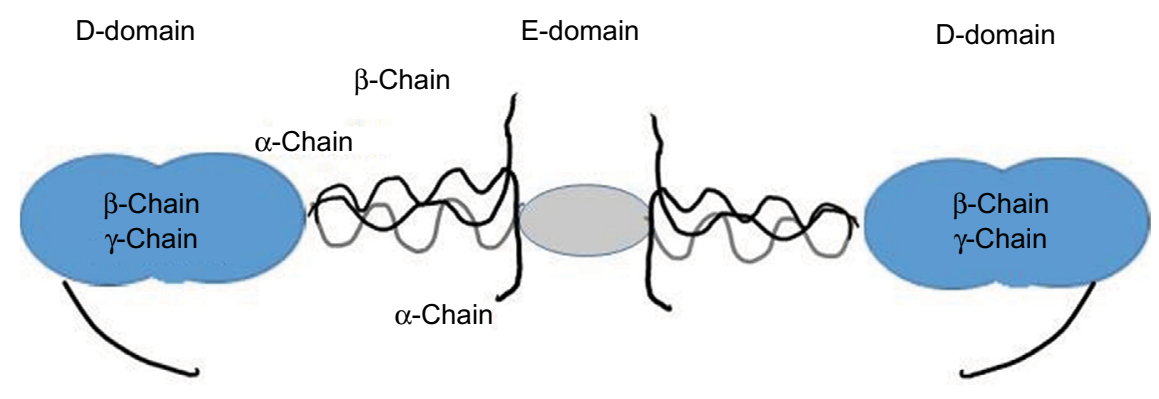

Figure I Schematic structure of the fibrinogen molecule. 
Table I Causes of hypofibrinogenemia and dysfibrinogenemia

\begin{tabular}{|c|c|c|c|}
\hline Condition & Cause & Examples & Phenotype \\
\hline Acquired & Reduced synthesis & Liver disease & Variable bleeding \\
\hline \multirow[t]{4}{*}{ hypofibrinogenemia } & Increased consumption & tPA therapy, cancer, sepsis with DIC & Variable bleeding, may be \\
\hline & & & prothrombotic or compensated \\
\hline & & & asymptomatic \\
\hline & Hemodilution & Massive transfusion & Variable bleeding \\
\hline
\end{tabular}

\begin{tabular}{|c|c|c|c|}
\hline \multirow[t]{4}{*}{$\begin{array}{l}\text { Acquired } \\
\text { dysfibrinogenemia }\end{array}$} & Assay interference & $\begin{array}{l}\text { Direct thrombin inhibitors (Dabigatran, } \\
\text { Bivalirudin, Argatroban), other thrombin } \\
\text { inhibitors (Heparin) }\end{array}$ & $\begin{array}{l}\text { Variable - may be asymptomatic or } \\
\text { have bleeding symptoms }\end{array}$ \\
\hline & Posttranslational modification & Abnormal sialylation in liver disease & $\begin{array}{l}\text { Variable - may be hemorrhagic } \\
\text { or prothrombotic (eg, portal vein } \\
\text { thrombosis) }\end{array}$ \\
\hline & Autoantibody formation & $\begin{array}{l}\text { MGUS or myeloma, autoimmune disease } \\
\text { (eg, SLE), drug induced }\end{array}$ & $\begin{array}{l}\text { Variable - may be asymptomatic or } \\
\text { present with bleeding symptoms. May } \\
\text { be associated with prothrombotic } \\
\text { phenotype in SLE }\end{array}$ \\
\hline & $\begin{array}{l}\text { Paraneoplastic structurally abnormal } \\
\text { fibrinogen production }\end{array}$ & $\begin{array}{l}\text { Cervical endothelial cells, hepatoma cells in } \\
\text { vitro }\end{array}$ & $\begin{array}{l}\text { May predispose to thrombosis } \\
\text { or bleeding. In vivo effect usually } \\
\text { confounded and unclear }\end{array}$ \\
\hline
\end{tabular}

Abbreviations: DIC, disseminated intravascular coagulation; tPA, tissue plasminogen activator; MGUS, monoclonal gammopathy of uncertain significance; SLE, systemic lupus erythematosus.

formation by an observer or the weight of the clot formed. Modern technology uses light transmission, absorbance, or mechanical end points for detection of clot formation on automated coagulometers or determination of the viscoelastic properties of whole blood.

The beginnings of fibrinogen determination as we know it today was when Hammarsten ${ }^{15}$ demonstrated the ability of thrombin to generate fibrin from any fibrinogen-containing solution. It is this concept that is still used in the commonly performed fibrinogen assays in the hemostasis laboratory.

Laboratory techniques have evolved in parallel with understanding of fibrin formation from fibrinogen (Figure 2). In the 19th century, separation of plasma and fibrinogen was recommended as it was believed that not all fibrinogen was converted to fibrin. The later recognition that all fibrinogen may be converted to fibrin moved fibrinogen estimation toward quantifying total fibrin produced. Initially, the weight of clots formed and subsequent extrapolation to amount of native fibrinogen was used. However, limitations existed in cases where coagulation factor deficiency was present. ${ }^{7,16}$

Assays available for fibrinogen determination range from the gravimetric washed clot and clottable protein methods to highly automated techniques performed on robotic analyzers. Gravimetric assays are technically demanding, time-consuming, and unsuitable for determination of fibrinogen in a larger number of samples. In situations where a rapid assessment of fibrinogen concentration is required, automated assays such as the Clauss and prothrombin time (PT)-derived fibrinogen are favored. ${ }^{17}$
Despite the limitations of the Clauss and PT-derived fibrinogen, these remain the two assays used most commonly in hospital laboratories. The Clauss depends on the thrombin-induced coagulation of plasma and resultant change in light absorbance. The high concentration of thrombin in conjunction with the diluted fibrinogen source from patient plasma means that the concentration of fibrinogen is the rate-limiting factor and, consequently, is the factor responsible for the time to clot in this system. Due to the dilution of the sample in the buffer, any interference by coagulation inhibitors is minimized in the Clauss assay. This includes therapeutic heparin as well as increased levels of fibrinogen degradation products that may be present in the patient sample, particularly in disseminated intravascular coagulation or thrombolytic therapy. The time to clot is converted to a fibrinogen concentration from a standard curve constructed using a standard of known fibrinogen concentration traceable to international standards. ${ }^{17}$

The PT-derived fibrinogen assigns a fibrinogen result indirectly using the change in optical density of the patient sample in the PT. Discrepancy between results in both assays is well documented, ${ }^{17}$ with the derived fibrinogen giving higher estimates of fibrinogen concentration compared to the Clauss fibrinogen, an effect that is more pronounced in certain patient groups such as those receiving oral anticoagulant therapy. ${ }^{18}$

A reduced result for fibrinogen by Clauss assay does not differentiate whether the decreased fibrinogen activity is caused by a reduced amount (hypofibrinogenemia) or a 


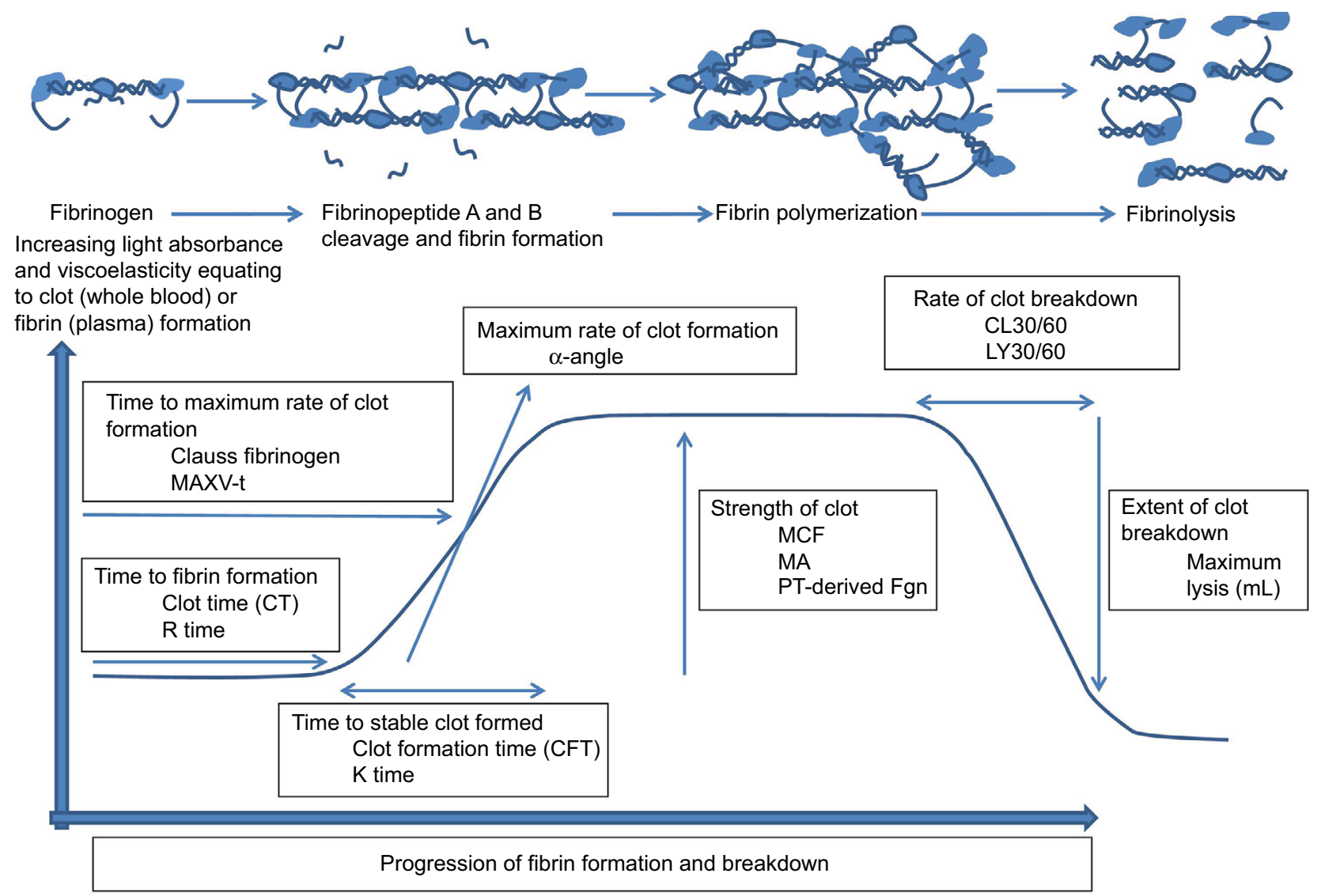

Figure 2 A schematic representation of the formation of a fibrin clot including time to initiate coagulation, rate of formation of fibrin, formation of the stable clot, and strength of the clot once formed. Individual parameters available for the assessment of fibrinogen status are annotated.

Notes: Phases of fibrin polymerization and breakdown and the parameters that can be used in conventional clotting assays and viscoelastic assays to quantify the fibrin polymerization and lysis process.

Abbreviations: MCF, maximum clot firmness; MA, maximum amplitude; PT, prothrombin time; MAXV-t, time to maximum velocity; Fgn, fibrinogen; R time, CT, time to clot.

dysfunctional protein present in normal amounts (dysfibrinogenemia). In situations where there is no personal or family history of reduced fibrinogen, and an acquired cause may be considered, differentiation between hypo- and dysfibrinogenemia can be important. To achieve this, a measure of the amount of protein present is required. Historically, this was done by clot weight or enzyme-linked immunosorbent assay (ELISA) but now automated latex agglutination methods are available.

More recently, the formation of fibrin and its viscoelastic properties are being utilized more for diagnosis and monitoring in clinical situations where inherited, or acquired, hypofibrinogenemia may be suspected. This is particularly in the situation of point-of-care testing in the cardiac and liver transplantation surgery setting.

Cardiac surgery poses a particular problem when attempting to determine whether there is a presence of acquired hypofibrinogenemia in the patient. While on cardiopulmonary bypass, the patient's blood is passed through a bypass circuit - a nonphysiological surface predisposing the patient's blood to contact activation and clot formation. To counteract this, very high doses of heparin are used to anticoagulate the blood upon removal from the patient. At the same time, during the surgery and partly through incomplete blockade of the patient's coagulation system, the patient consumes fibrinogen, which may result in critically low fibrinogen levels during or after completion of surgery. At the same time, residual heparin in the patient's blood may reduce the fibrinogen level detectable by the Clauss fibrinogen assay due to the inhibition of thrombin within the reagent, resembling the above states of dysfibrogenemia (Figure 3). ${ }^{19}$

Alternative anticoagulation by direct thrombin inhibitors ([DTIs] such as Bivalirudin or Argatroban) can be used in place of high-dose heparin during cardiopulmonary bypass, for instance, in patients with heparin-induced thrombocytopenia. Whereas heparin can be overcome with Hepzyme (a bacterial enzyme that inactivates heparin specifically) or protamine, the alternative DTI drugs cannot currently be reversed, and the residual-free DTI in patient plasma directly acts upon the thrombin added in the analytical reagent. In the 


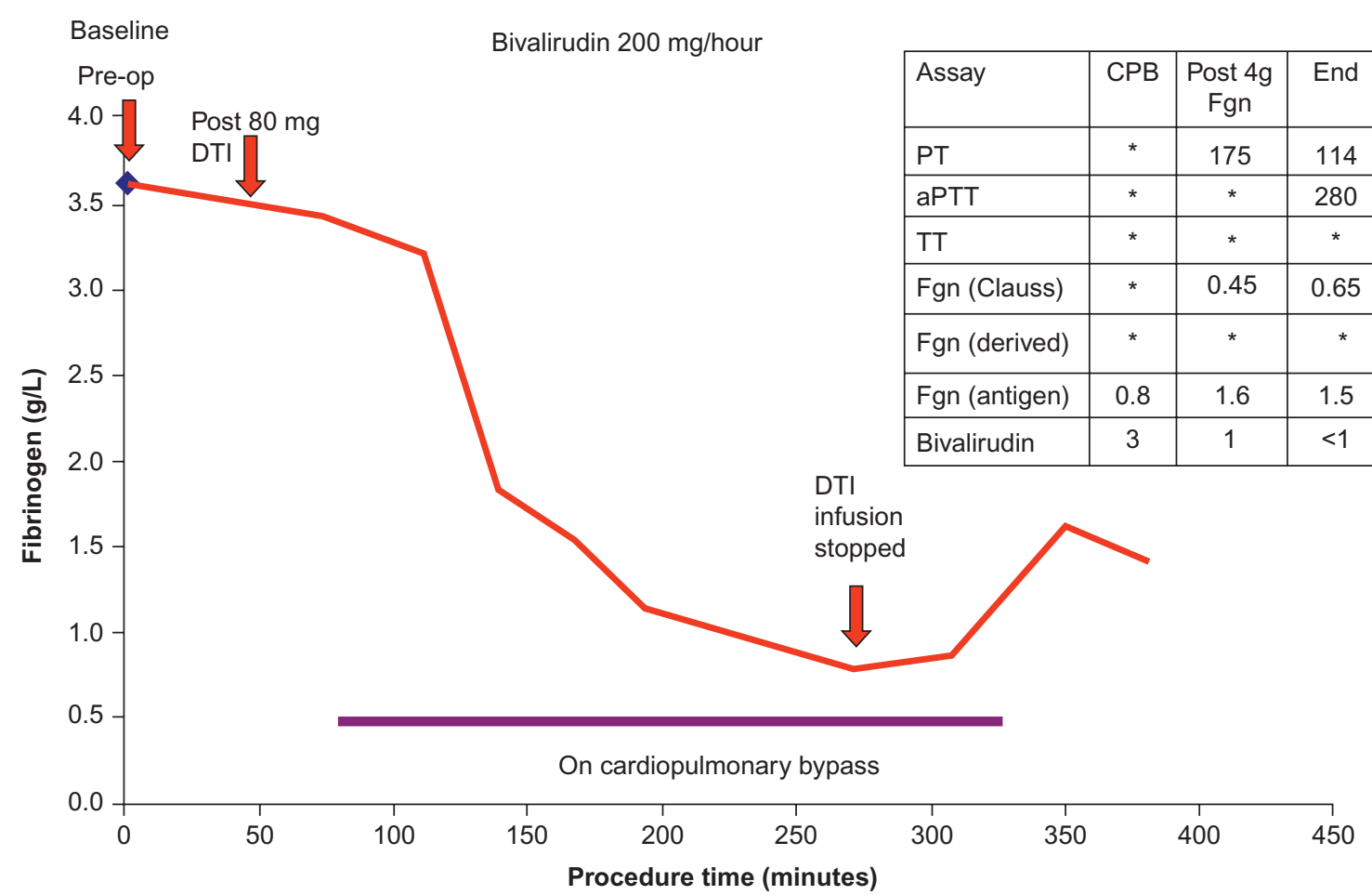

Figure 3 Determination of fibrinogen level (latex agglutination) during cardiopulmonary bypass in a patient anticoagulated with high-dose direct thrombin inhibitor (DTI Bivalirudin).

Notes: No fibrinogen level was available when tested using the prothrombin-derived fibrinogen assay. Although a result was obtained using the Clauss method, it was substantially lower than that determined using the latex agglutination assay. This is due to DTI inhibition of thrombin in the Clauss assay. The latex assay was useful to ensure that consumption due to active bleeding was not being encountered although the activity of the fibrinogen infused is still under debate as the inhibition of the thrombin in the reagent would be expected to also be affecting the thrombin generation within the patient. *Not available.

Abbreviations: PT, prothrombin time; aPTT, activated partial thromboplastin time; Pre-op, preoperative; CPB, cardiopulmonary bypass; Fgn, fibrinogen; TT, thrombin time.

situation where a fibrinogen result is required, measurement of the amount of fibrinogen (but not the activity) is possible by performing a latex agglutination assay on an automated coagulometer. Historically, the amount of fibrinogen may have been measured by the clot weight assay or more recently by enzyme-linked immunosorbent assay. However, the provision of a latex bead coated with an antibody to fibrinogen affords a quick and automated assessment of fibrinogen status and may guide replacement therapy if deemed necessary (Table 1$).^{20}$

\section{Contrasting techniques for determining fibrinogen level in viscoelastic assays}

In viscoelastic assays (VCAs), platelets and fibrinogen jointly affect the clot stability (Figures 2 and 4). Whole blood is placed in a cup and allowed to clot with or without additional reagents. The cup is continuously oscillated against a central pin (or vice versa), and as the clot formation occurs, the force is continuously measured and plotted by a computer resulting in a glass of cognac appearance, bell-shaped, curve. ${ }^{21}$ The fast turnaround time and the fact that VCA can be performed in whole blood rather than platelet-poor plasma and therefore are available at the point of care have led to the introduction of these methods into theaters and emergency rooms for patients at risk of or with massive hemorrhage, such as in cardiothoracic surgery, trauma, and obstetric hemorrhage. ${ }^{21}$

Modifications of the two main technologies, rotational thromboelastometry (ROTEM) and thromboelastography (TEG), have developed assay modifications that allow separation of the contribution of the fibrinogen level from the platelet effect in whole blood (functional fibrinogen TEG $^{\circledR}$ or FIBTEM $^{\circledR}$ ROTEM). In native TEG or ROTEM, the k-time/ clot formation time and $\alpha$-angle, as well as the maximum amplitude/maximum clot firmness are influenced by fibrinogen function. Using the TEG, the functional fibrinogen assay uses an added glycoprotein IIb/IIIa antagonist (abciximab) to separate platelet function and fibrinogen contribution. FIBTEM (Tem International GmbH, München, Germany) is often used to monitor the contribution of fibrinogen to clot formation, while the contribution of platelets is inhibited by cytochalasin D. ${ }^{22}$ In these assays, the remaining functional fibrinogen level becomes proportionate to the amplitude (maximum amplitude or maximum clot firmness) of the bellshaped curve. A normal result is typically available between 7 and 10 minutes (Figure 4). 


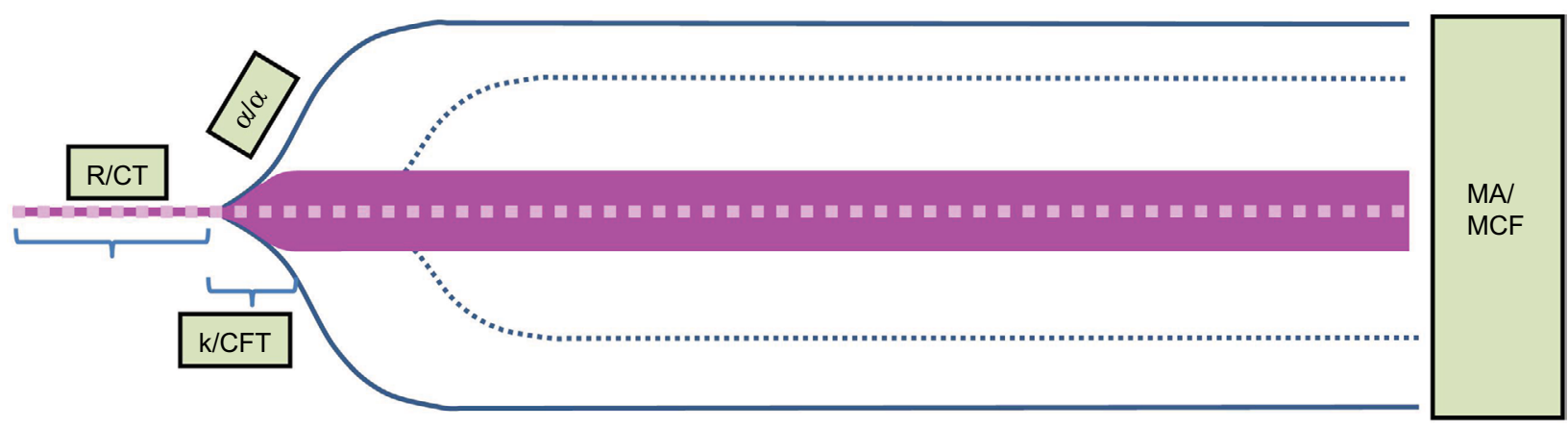

Dabigatran

Hypofibrinogenemia (predominantly affecting MA/MCF [FIBTEM])

Heparin $>4 \mathrm{u} / \mathrm{mL}$

Platelet dysfunction (no effect on FIBTEM/functional fibrinogen)

Normal

口DU Hypofibrinogenemia

FIBTEM/functional fibrinogen

प्वप FIBTEM/functional fibrinogen - hypofibrinogenemia $\alpha-$ angle of rate of clot formation

ROTEM

CT - clot time

CFT - clot formation time

MCF - maximum clot firmness

TEG

$\mathrm{R}-\mathrm{r}$ time (to clot)

$\mathrm{MA}$ - maximum amplitude

$\mathrm{K}$ - time to clot formation

Figure 4 Schematic representation of a ROTEM/TEG FIBTEM/functional fibrinogen plot with parameters and the effect of drugs and deficiencies on the various phases and parameters of the assay.

The assays are highly correlated but not completely interchangeable, this is in part due to the sample substrate being whole blood in VCA and platelet-poor plasma in the Clauss, and when comparing VCAs, there are additional mechanical and methodological reasons that affect the torsion force to millimeter translation in the plot, and whether or not there is possible residual platelet contribution to the amplitude even after addition of the above reagents..$^{23,24}$

\section{Interference of hypofibrinogenemia in other laboratory assays}

There are a number of assays where the interaction with low fibrinogen levels are not immediately apparent to the test's requester but are an important preanalytical variable (Table 2).

These assays may be clot based, chromogenic, or immunological. An acquired hypofibrinogenemia will impact only on the clot-based assays. Severe hypofibrinogenemia $(0.5 \mathrm{~g} / \mathrm{L})$ will result in failure of the assay to clot.

Such affected assays are lupus anticoagulant assays (dilute Russell viper venom time/silica clotting time, and so on) and activated protein $\mathrm{C}$ resistance assays. Immunological (generally latex agglutination) assays such as protein $\mathrm{S}$ are unaffected.

Chromogenic assays are variable to how they are affected. This is dependent on the type of assay and its constituent reagents and also, importantly, the cause of acquired hypofibrinogenemia or dysfibrinogenemia.

\section{Treatment}

Until very recently, a general transfusion threshold of $1 \mathrm{~g} / \mathrm{dL}$ was advocated as an indication to treat hypofibrinogenemia in the context of a bleeding patient. ${ }^{25} \mathrm{~A}$ number of experts and reviews recommend a more generous threshold for fibrinogen replacement, pushing the boundary to $1.5 \mathrm{~g} / \mathrm{dL}$ or even $2 \mathrm{~g} / \mathrm{dL}$ from the previously accepted threshold for transfusion of $1.0 \mathrm{~g} / \mathrm{dL}$ in massive transfusion. ${ }^{26}$ The threshold adopted will in part depend on the preferred analytical method to trigger transfusion (ie, viscoelastic- or laboratory-based Clauss assay as above). A dose-response is demonstrable across a wide range of baseline fibrinogen levels in vitro ${ }^{27,28}$ in the form of clot rate or maximum clot firmness, but it is not entirely clear 
Table 2 Impact of hypofibrinogenemia on important laboratory assays

\begin{tabular}{|c|c|c|c|}
\hline Type of assay & $\begin{array}{l}\text { Impact of acquired } \\
\text { hypofibrinogenemia }\end{array}$ & $\begin{array}{l}\text { Example (including but not } \\
\text { limited to) }\end{array}$ & Comments \\
\hline Clot based & Extensive & PT, aPTT, factor assays & $\begin{array}{l}\text { Severe }(<0.7 \mathrm{~g} / \mathrm{L}) \text { fibrinogen may lead to failure of } \\
\text { the sample to clot }\end{array}$ \\
\hline Immunological & Dependent on assay performed & Protein S, VWF, fibrinogen antigen assays & Fibrinogen antigen will be reduced \\
\hline Chromogenic & Limited & Protein C, antithrombin (II based) & $\begin{array}{l}\text { Dabigatran causes a falsely low fibrinogen and } \\
\text { apparent acquired hypofibrinogenemia if it is not } \\
\text { known that the patient is taking it. Additionally, } \\
\text { spurious inhibition of thrombin in the antithrombin } \\
\text { assay leads to a falsely elevated antithrombin level }\end{array}$ \\
\hline Chemiluminescent & None & HIT screen, D-Dimer & \\
\hline
\end{tabular}

Abbreviations: PT, prothrombin time; aPTT, activated partial thromboplastin time; VWF, von Willebrand factor; HIT, heparin-induced thrombocytopenia.

if this in vitro effect translates into additional patient benefit. The implications of increasing the threshold of fibrinogen replacement for the potentially eligible patients are wide. In our hospital, $1.5 \mathrm{~g} / \mathrm{dL}$ is very close to the lower limit of normal for healthy volunteers, making the vast majority of major bleeders eligible for fibrinogen replacement.

The plasma product of choice for fibrinogen replacement varies between countries depending on the regulatory framework. Fresh frozen plasma also contains fibrinogen and is available in all hospital settings and is comparatively cheap but requires the administration of large quantities of fluid to achieve a reasonable fibrinogen dose. ${ }^{29}$

In a mathematical model, it was illustrated that the total amount of body fibrinogen will depend on blood volume and plasma concentration and that the relative efficacy of any given intervention is diminishing as the target concentration is approaching the concentration of clotting factor in the concentrate. ${ }^{2}$

Two strategies are employed to produce a $10 \times$ more concentrated replacement treatment: ${ }^{30}$ the production of cryoprecipitate by thawing fresh frozen plasma at $4^{\circ} \mathrm{C}$ rather than at room temperature and plasma fractionation to concentrate fibrinogen. Both products are by-products of the production of other plasma products such as a factor VIII/von Willebrand factor concentrate (cryoprecipitate) $)^{31}$ and albumin (Cohn plasma fractionation). ${ }^{32}$ Their original introduction did not follow modern licensing procedures. Contamination of large plasma batches with hepatitis in the 1970s caused a variation in practice across political borders in that some regulators decided to abandon the pooling of large numbers $(>10,000)$ of plasma products in favor of the 5-10 donor exposure cryoprecipitate without, however, first demonstrating noninferiority in a clinical trial in terms of efficacy. ${ }^{33}$ There are no advantages in terms of total volume and a slight advantage in terms of ease of storage and preparation of fibrinogen concentrate in that it is blood group-independent and can easily be returned if not needed, whereas cryoprecipitate is blood group-specific and has to be discarded within a few hours of thawing if unused. Both the preparation and reconstitution of fibrinogen concentrate (endothermic reaction) ${ }^{34}$ and cryoprecipitate are time-consuming, so the time to infusion from request is only slightly reduced when using fibrinogen concentrate; however, it can be stored at room temperature and can potentially be stored in a theater or accident and emergency department provided the tracking of the product is ensured in case of later concerns about product safety. In countries where fibrinogen concentrate retains a license for the correction of acquired hypofibrinogenemia, it is the product of choice, whereas in countries, where the license has been lost in favor of cryoprecipitate, the latter is used. There has never been a large randomized controlled trial of fibrinogen concentrate against cryoprecipitate, although recently a small randomized pilot study in children after cardiac surgery was published that showed equivalence.$^{35}$ It is striking that despite achieving licensed status in the 1960s in a number of countries, it has only been in the first and second decade in the 21 st century that research into this component as an important treatment has been begun.

The highest accepted transfusion threshold is in pregnancy where currently, the experts agree a threshold of $2.0 \mathrm{~g} / \mathrm{dL}$ is considered sufficient to maintain normal hemostasis.

Cryoprecipitate would appear more cost-effective in the UK. The cost advantage, however, is lost in patients born after January 1, 1996, as the national recommendation is to use methylene blue-treated non-UK-plasma products. ${ }^{36}$ Particularly, before these patients constitute the majority of blood recipients, it is a major challenge to keep sufficient stock of MB-treated cryoprecipitate of the optimal blood group without causing wastage due to expiry, and there is a stringent requirement to infuse this within 4 hours of thawing. MF plasma products are approximately $5 \times$ as expensive as UK-based plasma products. Supporters of the fibrinogen 
concentrate cite the pasteurization step that has now made this product potentially safer than cryoprecipitate and the fact that the pooling reduces the risk of an infectious dose of pathogen in a given batch; however, this of course depends on the pathogen in question and maybe a disadvantage at the same time in case of an emerging public health threat. ${ }^{37}$

The information on the relative fibrinogen content of the blood products versus the blood components is conflicting. Cryoprecipitate may contain a significant amount of fibrinogen but shows a considerable degree of batch-to-batch variation. Fibrinogen concentrate on the other hand is highly predictable in its efficacy but more expensive (by a factor of 3-4) compared to a dose of cryoprecipitate based on fibrinogen content, at least in the UK. ${ }^{28}$

\section{Achieving supranormal fibrinogen levels}

There is evidence that clot strength and clot formation rates are optimal when fibrinogen is at $3 \mathrm{~g} / \mathrm{dL}$. Also, there is evidence that late low-dose administration in the context of massive blood loss is probably not effective despite a correlation of blood loss to the lowest fibrinogen level observed.$^{30} \mathrm{Of}$ note is also that there were no thromboembolic complications following fibrinogen replacement.

Two studies have recently attempted in cardiac ${ }^{38}$ and obstetric patients ${ }^{39}$ to preemptively administer $2 \mathrm{~g}$ of fibrinogen concentrate with no discernible benefit.

Some studies have reported reduced thrombin generation by calibrated automated thrombography despite hemostatic efficacy after administration, which is intriguing given the additional nonsubstrate-binding sites in the D- and E-domains and could suggest a more complex relationship between fibrinogen level and activity after replacement. ${ }^{40}$ There is conflicting evidence that exogenous fibrinogen administration decreases the endogenous fibrinogen production in pigs. ${ }^{41}$ Additionally, the precise timing of the intervention may reduce surgical blood loss further if given early; however, the effect will also depend on the type of injury. ${ }^{42,43}$

Restoration of fibrin clot formation as measured using viscoelastic testing was dependent on fibrinogen dose in a porcine model. ${ }^{44}$

\section{Outlook}

Fibrinogen is the most important coagulation protein to affect clot stability. In the research setting, the Clauss assay is the gold standard against which the other assays are benchmarked. In the acute clinical setting, the most clinically relevant measurement of fibrinogen level is currently under debate.
VCA assays have now been validated in cardiothoracic surgery to show sufficient precision, ${ }^{45,46}$ but the optimal clinical use of these techniques and whether these should be used in isolation or combination with laboratory-based assays remain unclear. Further research should focus on addressing the optimum replacement strategy independent of the question of which method is optimal for perioperative quantification, although ultimately these two questions may not prove to be clinically separable due to the practicalities of product provision, storage, and administration, which have the potential to significantly influence the observed clinical efficacy in a given study. ${ }^{44,47,48}$

\section{Disclosure}

Dr M Besser has received a fee from Glaxo Smith Kline for chairing a meeting and has previously received a travel grant from CSL Behring. The authors report no other conflicts of interest in this work.

\section{References}

1. Mosesson MW. Fibrinogen and fibrin structure and functions. JThromb Haemost. 2005;3(8):1894-1904.

2. Collins PW, Solomon C, Sutor K, et al. Theoretical modelling of fibrinogen supplementation with therapeutic plasma, cryoprecipitate, or fibrinogen concentrate. Br J Anaesth. 2014;113(4):585-595.

3. Cunningham MT, Brandt JT, Laposata M, Olson JD. Laboratory diagnosis of dysfibrinogenemia. Arch Pathol Lab Med. 2002;126(4):499-505.

4. Manco-Johnson MJ, Dimichele D, Castaman G, et al. Pharmacokinetics and safety of fibrinogen concentrate. J Thromb Haemost. 2009;7(12):2064-2069.

5. Idris SF, Hadjinicolaou AV, Sweeney M, Winthrop C, Balendran G, Besser M. The efficacy and safety of cryoprecipitate in the treatment of acquired hypofibrinogenaemia. Br J Haematol. 2014;166(3):458-461.

6. Grottke O, Braunschweig T, Henzler D, Coburn M, Tolba R, Rossaint R. Effects of different fibrinogen concentrations on blood loss and coagulation parameters in a pig model of coagulopathy with blunt liver injury. Crit Care. 2010;14(2):R62.

7. Mackie IJ, Kitchen S, Machin SJ, Lowe GD. Guidelines on fibrinogen assays. Br J Haematol. 2003;121(3):396-404.

8. Macfarlane RG, Biggs R. A thrombin generation test; the application in haemophilia and thrombocytopenia. J Clin Pathol. 1953;6(1):3-8.

9. Faraday N. Fibrinogen concentrate and allogeneic blood transfusion in high-risk surgery. Anesthesiology. 2013;118(1):7-9.

10. Hunault-Berger $M$, Chevallier $P$, Delain $M$, et al. Changes in antithrombin and fibrinogen levels during induction chemotherapy with $\mathrm{L}$-asparaginase in adult patients with acute lymphoblastic leukemia or lymphoblastic lymphoma. Use of supportive coagulation therapy and clinical outcome: the CAPELAL study. Haematologica. 2008;93(10):1488-1494.

11. Beinart G, Damon L. Thrombosis associated with L-asparaginase therapy and low fibrinogen levels in adult acute lymphoblastic leukemia. Am J Hematol. 2004;77(4):331-335.

12. Rodeghiero F, Castaman G, Dini E. Fibrinopeptide A changes during remission induction treatment with L-asparaginase in acute lymphoblastic leukemia: evidence for activation of blood coagulation. Thromb Res. 1990;57(1):31-38.

13. Ludlam CA, Bennett B, Fox KA, Lowe GD, Reid AW. Guidelines for the use of thrombolytic therapy. Haemostasis and Thrombosis Task Force of the British Committee for Standards in Haematology. Blood Coagul Fibrinolysis. 1995;6(3):273-285.

14. Dear A, Brennan SO, Sheat MJ, Faed J, George PM. Acquired dysfibrinogenemia caused by monoclonal production of immunoglobulin $\lambda$ light chain. Haematologica. 2007;92(11):e111-e117. 
15. Hammarsten O. Ueber das Fibrinogen I. Erster Abschnitt. Pfluegers Arch Ges Physiol. 1879;19:563-622.

16. Owen CA. History of Blood Coagulation. Roechester, MN: Mayo Clinic; 2001.

17. Mackie IJ, Kitchen S, Machin SJ, Lowe GD. Haemostasis, Thrombosis Task Force of the British Committee for Standards in H. Guidelines on fibrinogen assays. Br J Haematol. 2003;121(3):396-404.

18. Chitolie A, Mackie IJ, Grant D, Hamilton JL, Machin SM. Inaccuracy of the 'derived' fibrinogen measurement. Blood Coagul Fibrinolysis. 1994;5(6):955-957.

19. Besser MW, Klein AA. The coagulopathy of cardiopulmonary bypass. Crit Rev Clin Lab Sci. 2010;47(5-6):197-212.

20. Macdonald S, Bannister N, Ortmann E, et al. Determination of fibrinogen level to guide replacement therapy in patients undergoing cardiopulmonary bypass with direct thrombin inhibitors. JThromb Haemost. 2013;11(s3).

21. Hans GA, Besser MW. The place of viscoelastic testing in clinical practice. Br J Haematol. 2016;173(1):37-48.

22. Ponschab M, Voelckel W, Pavelka M, Schlimp CJ, Schochl H. Effect of coagulation factor concentrate administration on ROTEM(R) parameters in major trauma. Scand J Trauma Resusc Emerg Med. 2015;23:84.

23. Harr JN, Moore EE, Ghasabyan A, et al. Functional fibrinogen assay indicates that fibrinogen is critical in correcting abnormal clot strength following trauma. Shock. 2013;39(1):45-49.

24. Solomon C, Fickenscher K, Ormonde L, Ranucci M. Validation of viscoelastic coagulation tests during cardiopulmonary bypass: comment. J Thromb Haemost. 2015;13(12):2279-2281.

25. Levy JH, Welsby I, Goodnough LT. Fibrinogen as a therapeutic target for bleeding: a review of critical levels and replacement therapy. Transfusion. 2014;54(5):1389-1405; quiz 1388.

26. Hunt BJ, Allard S, Keeling D, et al. A practical guideline for the haematological management of major haemorrhage. $\mathrm{Br} J$ Haematol. 2015;170(6):788-803.

27. Kalina U, Stohr HA, Bickhard H, et al. Rotational thromboelastography for monitoring of fibrinogen concentrate therapy in fibrinogen deficiency. Blood Coagul Fibrinolysis. 2008;19(8):777-783.

28. Besser MW, Ortmann E, Klein AA. Haemostatic management of cardiac surgical haemorrhage. Anaesthesia. 2015;70 Suppl 1:87-95, e29-31.

29. Mallaiah S, Barclay P, Harrod I, Chevannes C, Bhalla A. Introduction of an algorithm for ROTEM-guided fibrinogen concentrate administration in major obstetric haemorrhage. Anaesthesia. 2015;70(2):166-175.

30. Leal-Noval SR, Casado M, Arellano-Orden V, et al. Administration of fibrinogen concentrate for refractory bleeding in massively transfused, non-trauma patients with coagulopathy: a retrospective study with comparator group. BMC Anesthesiol. 2014;14:109.

31. Pool JG. Cryoprecipitate in the treatment of hemophilia. Calif Med. 1970;113(2):66-67.

32. Cohn EJ, Oncley JL, Strong LE, Hughes WL, Armstrong SH. Chemical, clinical, and immunological studies on the products of human plasma fractionation. I. the characterization of the protein fractions of human plasma. J Clin Invest. 1944;23(4):417-432.

33. Yasunaga $\mathrm{H}$. Risk of authoritarianism: fibrinogen-transmitted hepatitis C in Japan. Lancet. 2007;370(9604):2063-2067.
34. Bruynseels D, Solomon C, Hallam A, et al. Commentary on reconstituting fibrinogen concentrate to maintain blinding in a double-blind, randomized trial in an emergency setting. J Emerg Med. 2016;50(1):104-107 e101.

35. Galas FR, de Almeida JP, Fukushima JT, et al. Hemostatic effects of fibrinogen concentrate compared with cryoprecipitate in children after cardiac surgery: a randomized pilot trial. J Thorac Cardiovasc Surg. 2014;148(4):1647-1655.

36. Idris SF, Hadjinicolaou AV, Sweeney M, Winthrop C, Balendran G, Besser M. Is the continued use of UK plasma sourced cryoprecipitate justified? Response to Makris. Br J Haematol. 2015;168(6):910-911.

37. Costa-Filho R, Hochleitner G, Wendt M, Teruya A, Spahn DR. Over 50 years of fibrinogen concentrate. Clin Appl Thromb Hemost. 2016;22(2): $109-114$.

38. Hanna JM, Keenan JE, Wang H, et al. Use of human fibrinogen concentrate during proximal aortic reconstruction with deep hypothermic circulatory arrest. J Thorac Cardiovasc Surg. 2016;151(2):376-382.

39. Wikkelso AJ, Edwards HM, Afshari A, et al. Pre-emptive treatment with fibrinogen concentrate for postpartum haemorrhage: randomized controlled trial. Br J Anaesth. 2015;114(4):623-633.

40. Tanaka KA, Egan K, Szlam F, et al. Transfusion and hematologic variables after fibrinogen or platelet transfusion in valve replacement surgery: preliminary data of purified lyophilized human fibrinogen concentrate versus conventional transfusion. Transfusion. 2014;54(1): $109-118$.

41. Martini WZ, Dubick MA. Fibrinogen concentrate administration inhibits endogenous fibrinogen synthesis in pigs after traumatic hemorrhage. J Trauma Acute Care Surg. 2015;79(4):540-547; discussion $547-548$.

42. Bolliger D, Tanaka KA. Haemostatic efficacy of fibrinogen concentrate: is it the threshold or the timing of therapy? Br J Anaesth. 2015;115(2): $158-161$.

43. Zentai C, Braunschweig T, Schnabel J, Rose M, Rossaint R, Grottke O. Fibrinogen concentrate does not suppress endogenous fibrinogen synthesis in a 24-hour porcine trauma model. Anesthesiology. 2014;121(4): 753-764.

44. Martini J, Maisch S, Pilshofer L, Streif W, Martini W, Fries D. Fibrinogen concentrate in dilutional coagulopathy: a dose study in pigs. Transfusion. 2014;54(1):149-157.

45. Rahe-Meyer N, Solomon C, Winterhalter M, et al. Thromboelastometryguided administration of fibrinogen concentrate for the treatment of excessive intraoperative bleeding in thoracoabdominal aortic aneurysm surgery. J Thorac Cardiovasc Surg. 2009;138(3):694-702.

46. National Institute for Health and Care Excellence. Detecting, Managing and Monitoring Haemostasis: Viscoelastometric Point-of-Care Testing (ROTEM, TEG and Sonoclot Systems). 2014. Available from: https:// www.nice.org.uk/guidance/dg13. Accessed August 31, 2014.

47. Aubron C, Reade MC, Fraser JF, Cooper DJ. Efficacy and safety of fibrinogen concentrate in trauma patients - a systematic review. J Crit Care. 2014;29(3):471 e411-477.

48. Wafaisade A, Lefering R, Maegele M, et al. Administration of fibrinogen concentrate in exsanguinating trauma patients is associated with improved survival at 6 hours but not at discharge. J Trauma Acute Care Surg. 2013;74(2):387-383; discussion 393-385.
Journal of Blood Medicine

\section{Publish your work in this journal}

The Journal of Blood Medicine is an international, peer-reviewed, open access, online journal publishing laboratory, experimental and clinical aspects of all aspect pertaining to blood based medicine including but not limited to: Transfusion Medicine; Blood collection, Donor issues, Transmittable diseases, and Blood banking logistics; Immunohematology; Artificial and alternative blood based therapeutics; Hematology; Biotechnology/nanotechnology of blood related medicine; Legal aspects of blood medicine; Historical perspectives. The manuscript management system is completely online and includes a very quick and fair peer-review system. Visit http://www.dovepress.com/ testimonials.php to read real quotes from published authors. 